\title{
Glossário de medicina natural: garrafadas vendidas na Feira da folha 28 na cidade de Marabá/PA
}

\author{
Glosario de medicina natural: botellas vendidas en la Feira da folha 28 \\ en la ciudad de Marabá/PA \\ Glossary of natural medicine: bottles sold at the Feira da folha 28 in the \\ city of Marabá/PA
}

\author{
Jucileide Barros de Loureiro ${ }^{1}$
}

\begin{abstract}
Resumo
Este artigo nasceu a partir de um estudo sobre os termos utilizados para nomear as ervas e produtos da medicina natural vendidos na feira da folha 28, localizada no bairro Nova Marabá, na cidade de Marabá, sul do Pará. Dentre os diversos produtos naturais comercializados, podem-se encontrar as famosas garrafadas, que consiste em uma combinação de ervas, que, segundo o conhecimento popular, juntas promovem a prevenção, o tratamento e a cura de algumas enfermidades. Para guiar-nos nessa pesquisa, teremos como base conceitos básicos para os estudos terminológicos, tais como conceitos sobre Lexicologia, Lexicografia, Terminologia, Terminografia e fraseologia. É de grande importância o estudo e a criação de glossários, para que o léxico de diferentes áreas de atuação seja registrado. No caso deste trabalho, serão analisados os termos, que é um subconjunto do léxico. Os Termos são signos linguísticos de uma área de conhecimento especializado, chamado de Língua de Especialidades, e são o objeto de pesquisa e estudo da Terminologia. Após tomar conhecimento sobre essas teorias, será apresentado uma amostra do glossário de medicina natural com alguns exemplos de termos de garrafadas. Por fim será feita a análise da construção morfológica e semântica desses termos. O objetivo deste estudo é analisar a construção de termos de uma prática muito comum no Brasil e que está presente no cotidiano das pessoas; observar as escolhas lexicais para a criação dos termos que nomeiam as garrafadas, bem como suas motivações semânticas é entender o contexto que cerca esta prática tão habitual na nossa sociedade. Além disso, deixar registrados esses termos provará a importância dos estudos lexicais, uma vez que o glossário poderá ser consultado e analisado em próximos estudos linguístico ou até mesmo da área da botânica e da medicina natural.
\end{abstract}

Palavras-Chave: Terminologia; Glossário; Medicina natural; Garrafadas.

\section{Resumen}

Este artículo nació de un estudio sobre los términos utilizados para nombrar hierbas y productos de medicina natural vendidos en la feria leaf 28, ubicada en el barrio Nova Marabá, en la ciudad de Marabá, en el sur de Pará. Entre los diversos productos naturales comercializado, se pueden encontrar las famosas botellas, que consisten en una combinación de hierbas que, según el conocimiento popular, promueven juntas la prevención, el tratamiento y la cura de algunas enfermedades. Para guiarnos en esta investigación, nos basaremos en conceptos básicos para estudios terminológicos, como conceptos sobre lexicología, lexicografía, terminología, terminología y fraseología. Es muy importante estudiar y crear glosarios para que se grabe el léxico de las diferentes áreas de especialización. En el caso de este artículo, analizaremos los términos, que es un subconjunto del léxico. Los términos son signos lingüísticos de un área de conocimiento especializado llamada Lengua de Especialidades, y son objeto de investigación y estudio de la terminología. Después de conocer estas teorías, se le presentará una muestra del glosario de medicina natural con algunos ejemplos de términos de botella. Finalmente analizaremos la construcción morfológica y semántica de estos términos. El objetivo de este estudio es analizar la construcción de términos de una práctica muy común en

\footnotetext{
1 Mestranda em Letras na Universidade Federal do Sul e Sudeste do Pará; Professora de Língua Portuguesa do município de São João de Pirabas, e do Estado do Pará; Marabá, Pará, Brasil; professorajuciloureiro@gmail.com.
} 
Brasil que está presente en la vida cotidiana de las personas; Observar las opciones léxicas para la creación de los términos que nombran las botellas, así como sus motivaciones semánticas, es comprender el contexto que rodea esta práctica tan común en nuestra sociedad. Además, dejar estos términos registrados demostrará la importancia de los estudios léxicos, ya que el glosario se puede consultar y analizar en futuros estudios lingüísticos o incluso en el área de botánica y medicina natural.

Palabras clave: terminología; Glosario; Medicina natural; Garrafadas.

\begin{abstract}
This paper was born from a study about terms used to named the herbs and natural medicine products sold at the fair of folha 28, located in the Nova Marabá neighborhood, in the city of Marabá, in the south of Pará. Among the various natural products commercialized, one can find the famous garrafadas, which consists of a combination of herbs, which, according to popular knowledge, together promote the prevention, treatment and cure of some diseases. To guide us in this research, we will base basic concepts for terminological studies, such as concepts on Lexicology, Lexicography, Terminology, Terminology, and Phraseology. In this work, we will analyze the terms, which is a subset of the lexicon. The Terms are linguistic signs of an area of specialized knowledge, called the Language of Specialties, and are the object of research and study of Terminology. After learning about these theories, a sample of the natural medicine glossary will be presented with some examples of bottle terms. Finally, we will analyze the morphological and semantic construction of these terms. The purpose of this study is to analyze the construction of terms of a practice very common in Brazil and that is present in the daily life of people; To observe the lexical choices for the creation of the terms that nominate the bottles, as well as their semantic motivations is to understand the context that surrounds this practice so habitual in our society. In addition, leaving these terms recorded will prove the importance of lexical studies, since the glossary can be consulted and analyzed in upcoming linguistic studies or even in the field of botany and natural medicine.
\end{abstract}

Key-words: Terminology; Glossary; Natural medicine; Garrafadas.

\title{
1. INTRODUÇÃO
}

A prática de retirar da mata subsídios para a alimentação, prevenção de doenças e cura para algumas enfermidades é uma prática bastante comum no nosso país.

"Na Amazônia, ainda temos chance de Manejar e usar a floresta para obter frutas, Madeira, Caça e remédios, além de outros benefícios(...) o valor dos produtos florestais como açaí, bacuri, e copaíba está crescendo rapidamente. Tanto nas feiras do interior como nas grandes cidades, existe a oportunidade de ganhar uma renda extra vendendo este produto" (SHANLEY, 2005, p.18).

Na feira da folha 28, situada no Bairro Nova Marabá, na cidade de Marabá, Pará, podemos encontrar barracas especializadas na venda de produtos naturais retirados da Floresta Amazônica e da Mata Atlântica. São produtos que vêm de todas as regiões do Brasil. Folhas, raspas de madeira, sementes, óleos, e garrafas preparadas, destinadas para cura e prevenção de enfermidades. Iremos refletir sobre os termos usados para nomear essas garrafadas. 
O termo é um subconjunto do léxico e pode ser definido como signo linguístico de uma área de conhecimento especializado, ou língua de especialidades, que neste trabalho será a terminologia de determinado produto da medicina natural.

"O léxico de uma língua inclui unidades muito heterogêneas - desde monossílabos e vocábulos simples até sequências complexas formadas de vários vocábulos e mesmo frases inteiras como é o caso de muitas expressões idiomáticas e provérbios." (BIDERMAN, 2005, p. 747). Perceberemos que os termos criados para designar as garrafadas são sequências complexas formadas por vários vocábulos, o que será chamado de Sintagmas Terminológico (S.T). Para analisar este pequeno glossário serão utilizados os conceitos básicos de Lexicologia, Lexicografia, Terminologia e Fraseologia.

\section{REFERENCIAL TEÓRICO}

\subsection{Lexicologia, Lexicografia}

A Lexicologia é o estudo do léxico das línguas englobando seus aspectos fonético e fonológico, semântico, morfológico, sintático e pragmático. Por meio dos léxicos de uma língua construímos frases, orações, discursos. É por meio do léxico que a comunicação é possível.

Para Costa (2012. P.36) "a Lexicologia pode ser definida como o ramo da linguística que se ocupa dos estudos científicos do léxico". Para Birdeman (1981, apud Costa, 2012), a lexicologia estuda todos os aspectos das palavras de uma língua, incluindo aspectos subjetivos, pragmáticos. Segundo Costa (2012), léxico são todos os vocábulos memorizados por um indivíduo que possibilita a transmissão de pensamentos, ideias, desejos e emoções a cada ato de fala.

Como bem denomina Biderman (1998, apud MATOS, 2001), lexicografia é a ciência que estuda os dicionários. Tão tradicional quanto a Lexicologia, porém sem o rigor científico. Lexicografia é a ciência responsável por analisar e criar os dicionários.

Segundo Costa (2012) a Lexicografia divide-se em dois ramos de pesquisa. O primeiro é a Lexicografia Prática que observa a produção de dicionários, vocábulos e glossários; o segundo é a Lexicografia Teórica ou Metalexicografia que se preocupa em estudar a elaboração e críticas de dicionários, a pesquisa da história e do uso dos dicionários. Esses ramos de estudo são ainda bastante recentes, e entre as questões 
estudadas neles vale a pena salientar a distinção existente entre Dicionário, Vocabulário e Glossário.

Segundo Barbosa (1995), o objetivo do Dicionário e reunir e definir um maior número de lexemas de uma língua; o vocabulário se preocupa em reunir o conjunto de lexemas de um determinado tipo de discurso (médico, político...), o glossário, por sua vez, se atenta a reunir lexemas usados em um determinado contexto. No caso deste trabalho, lexemas, ou como chamaremos a seguir, termos usados na medicina natural, as chamadas garrafas.

\subsection{Terminologia, socioterminologia}

A Princípio, a terminologia foi um estudo de Wuster (1931), destinado à sua tese de doutoramento. "Wuster já tentara alcançar, através da utilização do esperanto, a univocidade da comunicação; sem sucesso, recorreu a uma metodologia para elaboração de glossários que assegurasse a padronização dos termos usados na ciência e na técnica" (MACIEL, 2007, p.372)

A Teoria Geral da Terminologia, criada após a sua morte dá ênfase as diferenças de abordagem de dois objetos distintos. O conhecimento e a Língua, contrapondo o saber científico e o saber comum. "Consequentemente coloca em pólos contrários, a língua comum, sujeita a falhas, lacunas, variação e a língua especializada, deliberadamente elaborada para transmitir, de maneira correta e eficiente, a informação científica e profissional (...)” (MACIEL, 2007,p.373).

Com o tempo, a terminologia começou a seguir o fluxo dos estudos linguísticos e precisou se adequar aos novos ramos de pesquisa. É então que passa-se a falar da socioterminologia, que segundo Maciel (2007) quer revisar a terminologia tradicional de Wuster, por um olhar social, livrando-a do rigorismo idealizado e reducionista. Passa a reconhecer, então, o contexto, a polissemia e a variação.

\subsection{Fraseologia}

Saussure, em seus estudos, já havia afirmado que a comunicação é possível devido a um encadeamento de caráter linear. Os Sintagmas, segundo Saussure (1988, apud Bevilacqua, 2005, p. 76) "podem corresponder a palavras, a grupo de palavras, a unidades complexas de toda dimensão e de toda espécie como as palavras compostas, derivadas, membros de frases e frases inteiras." 
Segundo Bevilacqua (2005), o autor já teria feito uma referência à importância da fraseologia para a comunicação. A autora discurso sobre a percepção de alguns autores, como Charles Bally (1951), Pottier (1978), Hausmann (1990) e Mel'Cuk (1984, 1988, 1992) sobre a fraseologia que para alguns está limitada às expressões idiomáticas de cada língua. Outros consideram os provérbios, os ditados populares as locuções e as lexias compostas. A autora afirma ainda que de grande importância conhecer a fraseologia da língua especializada, pois demonstra uma competência linguística em determinada matéria ou temática. Será explanado a seguir um breve linear a respeito da fraseologia da língua comum e da língua especializada.

A fraseologia, mesmo sendo um campo de estudo recente, vem sendo citada há algum tempo. Estudioso como Charles Bally (1951), propôs dois tipos de unidades ou locuções fraseológicas, pois segundo ele, associações e agrupamentos podem ser de dois tipos: passageiros ou indissolúveis. Os passageiros são as séries fraseológicas ou agrupamentos usuais que apresentam grau de coesão relativo e as que a compõe tem autonomia quando isoladas, exemplo "amar loucamente". Os indissolúveis são as unidades fraseológicas que apresentam grau de coesão absoluto. Nesse tipo, as palavras perdem a significação quando isoladas e é o conjunto que adquiri novo significado, exemplo "Ainda a pouco", "com certeza". Pottier (1978) propõe quatro tipos de lexias: a simples, a composta, a complexa e a textual. O grupo das lexias textuais é a que corresponde às unidades fraseológicas, cujo o significado deriva do conjunto.

Outros autores mais atuais também são de grande importância para o estudo da fraseologia. Hausmann (1990), defende a ideia de que essas colocações, como ele nomeia, são formadas por um elemento base e um elemento co-ocorrente, sendo que a base é autônoma e o co-ocorrente está restringido ao primeiro. Este autor considera que essas colocações não podem ter seu significado deduzido de forma independente por cada elemento que a compõe, somente pelo conjunto. Ele propõe, também, determinadas estruturas morfossintáticas que auxiliam no seu reconhecimento, como: substantivo + substantivo; substantivo + adjetivo; verbo + substantivo; verbo + Advérbio.

Mel'Cuk $(1984,1988,1992)$ atribui uma função lógica que possui um valor para cada unidade léxica pela fórmula $\mathrm{f}(\mathrm{x})=\mathrm{y}$, onde $\mathrm{f}$ é a função léxica; $\mathrm{X}$ é o lexema ou uma locução; Y é o valor da função. "Assim, a unidade ruído infernal pode ser explicada pela existência da função Magn, que é a função léxica que indica intensidade, grau elevado, cujo valor é indicado por infernal e que se aplica ao lexema ruído. Sua representação, segundo esta proposta, é: Magn (ruído) = infernal. 
Para finalizar os conceitos de fraseologia da língua comum, Benson, Benson e Ilson (1996, apud Bevilacqua, 2005) caracterizam essas unidades, principalmente, pelo grau de fixação por determinadas estruturas morfossintáticas, se assemelhando com a proposta de Hausmann

\section{METODOLOGIA DE ORGANIZAÇÃO DO GLOSSÁRIO}

\subsection{Seleção e organização do Corpus}

Os termos selecionados para as entradas deste glossário são as garrafadas vendidas na feira da 28, localizada na Folha 28, bairro Nova Marabá, Marabá/Pará.

\subsection{Organização dos termos na Macroestrutura}

A macro estrutura deste glossário foi organizada de forma sistemática, usando o programa Lexiquepro. Os termos de entrada são os nomes das garrafadas e estão dispostos em ordem alfabética, obedecendo a escrita do rótulo dos produtos, acompanhados das informações gramaticais e definições.

Para a definição, foi usada a indicação de uso das garrafadas.

\subsection{Organização dos termos na microestrutura}

Os verbetes do glossário estão organizados da seguinte: TERMO-ENTRADA +INFORMAÇÃO GRAMATICAL + DEFINIÇÃO + VARIANTE (quando houver) EX:

Aguardente alemã S.T Purgativo e laxativo indicado para o tratamento de indigestão do estômago, fígado, baço afetado, congestão, derrame cerebral, paralisia nas pernas, braços e mãos com tremedeira. Dores de cabeça, enxaqueca e fastio.

- Variante : Tintura de jalapa composta.

\subsection{Abreviaturas e sinais gráficos:}

S.T: Sintagma terminológico

s.m: Substantivo masculino

variante 
RELACult - Revista Latino-Americana de Estudos em Cultura e Sociedade

\section{AMOSTRA DO GLOSSÁRIO DAS GARRAFADAS}

$\mathbf{A}-\mathbf{a}$

Aguardente alemã s.t. Indicada como purgativo, laxantivo, Aguardente alemã Purgativo e laxativo indicado para o tratamento de indigestão do estômago, fígado, baço afetado, congestão, derrame cerebral, paralisia nas pernas, braços e mãos com tremedeira. Dores de cabeça, enxaqueca e fastio.

Variante : Tintura de jalapa composta.

$\mathbf{C}-\mathbf{c}$

Cerveja preta medicinal S.T. Indicado na prevenção de indigestão no estômago, fígado, baço afetado com congestão, derrame cerebral, paralisia facial como boca torta;'pernas, braços, mãos com tremedeira, dores de cabeça, enxaqueca, fastio e menopausa.

Cura tosse lambedor composto s.t. composto de ervas indicado para problemas respiratórios, tais como asma, falta de ar, bronquite, cansaço, chiado no peito, infecções pulmonares.

$\mathbf{E}-\mathbf{e}$

\section{Elixir Antireumático}

S.T. Indicado como agente diurético, depurativo, sudorífico, anti-inflamatório e antireumático. eficiente nos casos de reumatismo crônico, artrite e dores nas juntas. Eficaz na eliminação de ácido úrico do organismo (gota).

Elixir Assacu S.T. Indicado para prevenção do câncer e no tratamento de miomas e tumores cancerigenos. Combate infecção de útero, ovários, trombas, cólicas menstuais. 
Elixir Açoita Cavalo (com beringela e acachofra) S.T. Indicado para baixar e controlar a taxa de colesterol . atua como coadjuvante nas dietas de emarecimento, pois aumenta a eliminação de gordura. A alcachofra diminue as dores hepáticas, estimula as funções do fígado e auxilia a diminuição da uréia.

Elixir Cabeça de negro S.T. Indicado como analgésico e anti-inflamatório, ação depurativa, desintoxicante do sangue, laxantivo, antioxidante, diurético, eficaz no tratamento de reumatismo, artrite, úlcera, dores no nervo ciático, , sífilis, dermatoses, diarréia, dilatação do estômago, dispepcia, doenças de pele, erisipela, escrufulose, hidropcia.

Elixir Energisex S.T. Energético afrodisíaco, tônico, estimulante do sistema nervoso; combate o sono excessivo, esgotamento físico e mental, dificuldade de raciocínio, concetração e impotência sexual.

Elixir flor de catingueira S.T. Indicado para doenças do estômago, gass, azia, boca amarga, ventosidade na barriga, , enjoos, latejamento e quentura, peso na barriga, , pontadas e dores na cabeça, peito eventre, excitação nervosa, escurecimento da vista, desmaios, zumbidos nos ouvidos, vertigens, ataques nervosos, estremecimentos, sensação de calor em diferentes partes do corpo; falta de ânimo, frio nos pés e mãos, manchas na pele, ataques de hemorróidas, etc.

Elixir Garrafada do Amapá

S.T. indicado para o tratamento de pneumonia, efizema de modo geral.

\section{Elixir mururé antireumático}

S.T. Indicado como agente diurético, depurativo, sudorífico, anti-inflamatório, e antireumático. Eficiente no caso de reumatismo crônico, artrites e dores nas juntas travadas. Indicado para eliminar excesso de ácido úrico do organismo.

\section{$\mathbf{G}-\mathbf{g}$}


Garrafada do índio S.T. Indicada para todo tipo de infecção como gastrite, úlceras, aderência dos rins, doenças intestinais, próstatas, bexiga, doenças venereas, útero, ovário, mioma, dor velha, mãe do corpo, menopausa, cólicas, anemias, regulados menstrual.

Garrafada 2 em 1 S.T. Indicada para reumatismo, dores na coluna, artrite, artrose, osteoporose, gastrite, úlcera, inflamações no útero e ovários, miomas, diabetes, colesterol, prostatite, combate células cancerígenas, age no sistema imunológico de modo geral deixando o organismo mais resitentes.

\section{$\mathbf{J}-\mathbf{j}$}

Jalapol s.m. composto de ervas que tem como base a erva Jalapa, indicado para doenças do estômago, fígado e baço e para aliviar sequelas de "derrame cerebral"(AVC), tais como paralisia facial, perda da fala, tremos nas pernas, braços e mão, dores de cabeça, dores na barriga, fastio, e para sintomas da menopausa. 
Sangria d'água

S.T. Indicada para inflamação nos ováros, cisto no ovário, miomas, corrimentos uterinos, cólicas uterinas, cicatrizes internas e ferida no útero.

Saúde da mulher S.T.. Indicado para inflamação do útero, ovários, trompas, rins, dores no corpo, nas pernas, corrimentos, cólicas mestruais, útero baixo. pode ser usado como regulador menstrual.

$\mathbf{X}-\mathbf{x}$

Xarope do cupim para asma

S.T. Indicado para problemas respiratórios, tais quais asma, tosse brava, grpe, faringite, bronquite, falta de ar, catarro crônico, pneumonia e garganta inflamada.

\section{CONCLUSÃO}

Esta amostra de glossário pode ser suficiente para se perceber a riqueza do léxico que está presente nesta importante cultura de se tirar da natureza a prevenção e a cura de algumas enfermidades. Produzir este vocabulário de Língua de Especialidade é o início de um estudo mais amplo do universo da medicina natural presente na nossa regi.

Os nomes das garrafadas, geralmente estão ligadas aos produtos utilizados nela, ou à sua indicação de uso, como veremos a seguir.

Pode-se observar que a formação dos termos das garrafadas é formada por agrupamentos complexos de palavras, que serão chamadas neste trabalho de Sintagma Terminológicos.

Esses grupos de palavras são indissolúveis, como explica Bally (1951, in BEVILACQUA, 2005), ou seja, possuem grau de coesão absoluto. Os grupos de palavras indissolúveis perdem a significação quando isoladas, é o conjunto de palavras que adquiri novo significado. Outra teoria da fraseologia que podemos aplicar na reflexão destes termos é a de HAUSMAN (1990, in BEVILACQUA, 2005), que propõe que os sintagmas são formados por um element base e outro (s) co-ocorrentes. Este autor também propõe determinadas estruturas morfossintáticas que podemos perceber também nos termos coletados, tais como: 


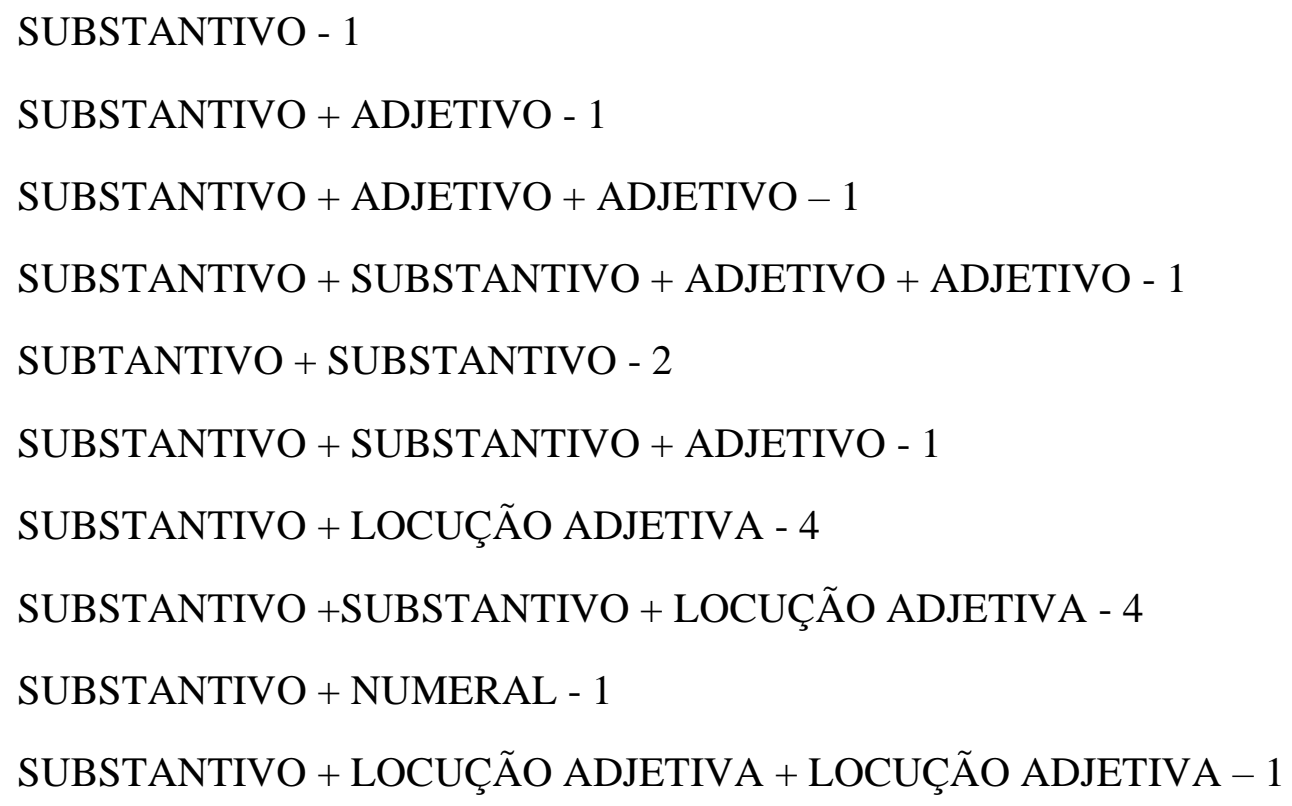

Sendo o número ao lado a quantidade de vezes que esse agrupamento foi percebido. Pode-se afirmar que a maioria dos termos para denominar as garrafadas medicinais são formados pela sequência SUBSTANTIVO + LOCUÇÃO ADJETIVA OU SUBSTANTIVO + SUBSTANTIVO + LOCUÇÃO ADJETIVA, sendo o substantivo o tipo de mistura (elixir ou garrafada) e a locução adjetiva a finalidade, indicação ou produto usado na garrafada, exemplo: Elixir Antirreumático, onde Elixir é o tipo de garrafada e antirreumático é a indicação, a finalidade da garrafada. 


\section{BIBLIOGRAFIA}

BARBOSA, Maria Aparecida. Contribuição ao estudo de aspecto da tipologia de obras lexicográficas. in: Revista Ciência da Informação. Vol 24, n. 3, 1995.

BEVILACQUA, Cleice Regina. Fraseologia: Perspectiva da língua comum e da língua especializada. Revista Língua e Literatura.V.6 e 7. nº 10/11. p. 73-86. 2004/2005.

BIDERMAN, Maria Teresa Camargo. Unidades complexas do léxico. in: Estudos em homenagem ao Professor Doutor Mário Vilela, vol. 2, 2005, pag. 747-757 in http://ler.letras.up.pt/uploads/ficheiros/4603.pdf acessado em 26 de junho de 2018.

COSTA, Raquel Pires. Estudo linguístico no litoral maranhense: léxico e cultura dos pescadores do município de Raposa. Dissertação. UFMG. 2012

MACIEL, Anna Maria Becker. Quais são os rumos da terminologia no século XXI. in: ISQUERDO, Aparecida Negri, ALVES, Ieda Maria(orgs). AS CIÊNCIAS DO LÉXICO: Lexicologia, Lexicografia, Terminologia.vol III. UFMS. MS. 2007.

SHANLEY, Patrícia. MEDINA, Gabriel. Frutíferas e Plantas Úteis na Vida Amazônica. Belém: CIFOR, Amazon, 2005. 
RELACult - Revista Latino-Americana de Estudos em Cultura e Sociedade

Revista Latinoamericana de Estudios en Cultura y Sociedad | Latin American Journal of Studies in Culture and Society V. 05, $\mathrm{n}^{\circ}$ 02, abr-ago., 2019, artigo $\mathrm{n}^{\circ}$ 1614 | claec.org/relacult | e-ISSN: 2525-7870 